possibility, one should not do so. In patients getting back s far as the clearing station with tourniquets applied, death of the limb from interruption of the circulation is almost invariable. Even if this does not occur, the cutting off of the blood supply from an area of smashed muscle provides all the ideal conditions for the development of gas gangrene.

Other measures than the tourniquet should therefore be adopted; and if for some reason a tourniquet has been applied it is the duty of every medical officer through whose hands the case passes to remove it. 'In most cases there will be no bleeding. If, however, bleeding recounmenees, then the following methods should be employed:

1. In many cases the obvious source is exposed in the woutind and may be seized with pressure forceps and ligatured. This is the ideal.

1.2. In other cases blood may be seen welling from a deep recess of the wound. Pressure forceps are applied in that artea and the bleeding ceases. To apply a ligature over the forceps may need a free opening up and present difficulties. In this case it is best to leave the forceps on and pack ronid with gauze. The patient is sent on with the forceps in situ.

i3. If neither of these methods is applicable pressure matist be obtained by packing the wound. But it is essential that the pack really presses on the bleeding point. It is no ase packing gauze through a small aperture into a big lecerated cavity. The pack must be cone-shaped, with its apex at the source of haemorrhage. If the wound aperture be small it must be enlarged by slitting up the skin and fascia. No anaestletic should be used. The pain caused is not great, particularly if the incision be made in a distal direction where the nerve supply has been interrupted by the injury. Gauze is then packed firmly into the wound and a pad placed over it. Firm pressure is made with a bandage, but a wide wooden splint should always be applied to the opposite side of the limb before the bandage is applied, in order to avoid constriction of the extremity.

\section{Special Cases.}

Penetrating Abdominal Wounds.-These should be sent by the shortest route to the clearing station. The mortality varies directly with the number of hours which intervenes between the receipt of the wound and operation. It is important to realize that not only wounds with their entrances in the abdominal wall, but also wounds of the back, buttock, hip, groin, and lower chest, are potential "perforating abdomens." Shock, out of proportion to the external appearance of the wound, pain in the abdomen, rigidity-especially in regions remote from the woundand vomiting, point to the likelihood of an abdominal lesion. Any case in which suspicion exists should be sent on at once.

Penetrating Chest Wounds.-An injection of morphine should be given. This lessens the respiratory distress. The patient should be placed in the position of greatest pomfort, which is usually the semi.recumbent posture. While it may be an advantage to keep a bad case for a time to allow him to tide over his initial shock, the general rule is to send cases back as soo as they are fit to travel. In dressing the wound, it is im portant to avoid the interference with the free play of the uninjured side of the chest caused by an encircling bandage. Use strapping when possible. There is one class of chest wound that needs special attention. The wound in the parietes may remain open so that air is sucked in and out with respiration, or the blood collected , in the pleural cavity may be leaking away through the external aperture. "Sucking pneumothorax" and "leak. ing haemothorax" are convenient terms for these conditions. In the first the respiratory embdrrassment is extreme, and the patient's condition desperate from the start. In the latter; iso long as there is a free external leak, internal bleeding is likely to continue. In both infec tion is certain if the condition continues. In both types of case the wound should be closed before the patient is sent on. Stout sutures inserted with lairge curved needles are used. A good grip should be obtained of skin and titiscle. If the gap be large, a piece'of gauze should be laid in the wound and the stitches tied over this. "When for any reason suture of the wound is impracticable, the wound: should be plugged with gauze, and strapping applied over it in the manner employed in strapping a broken rib.
It should be practicable thus to render the wound air tight:- The improvement in a patient's condition brouglst about by suturing a sucking pneumothorax is immediate and dramatic.

Penetrating Wounds of the Knee.joint.-Great care must - be taken to splint all cases in which joint injury is suspected. It is easy to diagnose a wound of the kneejoint when the synovial cavity is distended with blood or effusion. It is very easy to miss such a case at an early stage, when there is nothing to see but a small entry wound in the lower part of the thigh. The matter is, however, of great moment. A knee-joint into which a missile has carried infection, is much less likely to run an aseptic course after operation if distension of the synovial cavity has opened up all its recesses to the scattering of infected material. Failure to splint favours bleeding, effusion, and distension. The unrecognized knee case sent down "walking" does badly. It is a safe rule to splint all penetrating wounds near the knee.

The Field Medical Cards.-In conclusion I should like to say a word about this card. It forms the means by which you are enabled to communicate to the unit behind you any information which may be useful in the further treatment of the case. Look at it from this point of view : "If I were in the unit behind, what information should I like to have about the previous history of this case?" Put that down on the field medical card. In most cases nothing is needed but your diagnosis. Above all write legibly. Put the important wound or wounds first and be precise. "G.S.W. abdomen, arm, both legs" may mean anything. It may mean "G.S.W. abdomen perforating, also arm, right thigh, left leg." It may mean "G.S.W. fracture right femur also abdominal wall, left arm, left leg"; or again, "G.S.W. fracture left tibia, right knee-joint, also abdominal wall, arm." Note the occurrence of serious bleeding and the means taken to arrest it. Note such a thing as a sucking pneumothorax. Note the dose of morphine in the special space, and the administration of antitetanic serum. In short, try to help the man behind you. He will be grateful, although perhaps, at times, he may seem to lack exuberance in showing it.

\section{ON GUNSHOT WOUNDS OF THE HEAD."}

T. O. GRAHAM, M.D., D.P.H., F.R.C.S.I., MAJOR R.A.M.C.(S.R.)

During ten months' experience at a general hospital nearly 500 cases of gunshot wounds of the head have passed through my hands. Whilst very encouraging results have been obtained in many instances in which extensive damage to cranium and brain had occurred, I have to admit that in about 50 per cent. of those cases in which the dura was opened by depressed or indriven frag. ments of bone, by the missile, or subsequently opened at operation, death ensued; but, so far as I liave been able to ascertain, my results compare favourably as regards mortality with those obtained by others engaged in operating on head injuries of war.

Cranial injuries may be classed in two main categories, according as tho dura remains intact or is opened and penetrated.

In my series of 500 cases in which trephining had to be resorted to, the mortality was less than 10 per cent. where the dura was intact, and just over 50 per cent. in those in which the dura was penetrated.

\section{Anaesthesia.}

It has become my practice to operate under local anaesthesia in nearly all cases. Two-thirds of a grain of omnopon is injected hypodermically half an hour. before operation. : When the patient is on the operating table, 2 per cent. norocain and adrenalin is injected into the scalp in a complete circle of infiltration all around the area to be operated on. In this way a circumferential zone of "blocked": nerves is produced. The conscious patient feels no pain either while excising the infected scalp wound, trephining or nibbling away the bone, incising the dura, 24th, 1917.
paper read at the Boujoga Bage Medical society A Agugt 
or removing fragments of bone and metal from the dis. integrated brain track. Moreover, this "barrage" infiltra. tion method affords efficient haemostasis during operation, and there are no post-operative ill effects, such as restlessness and vomiting, which are so frequent after general anaesthesia. The patient can also be made to sit up in bed immediately after the operation. Recently I have only had to have recourse to general anaesthesia when the patient was very restless and semi-conscions.

The Operative Procedures.

In all cases it is essential that the lacerated scalp wound should be freely excised, in order to ensure an area as free from sepsis as possible for further intracranial inter. ference. In most cases these further measures may be proceeded with by simply extending the original excised scalp wound and retracting the edges of the elliptical incision so produced. A wider area of bone may be exposed by a lateral incision at right angles to the ellipse, thus producing a triradiate incision. In some cases it may be preferable to turn down a wide flap denuding the bone of its pericranium. The subsequent measures to be arlopted will be indicated by: (a) The findings of previous stereoscopic $x$-ray plates. In this connexion $I$ cannot speak too highly of Captain H. E. Gamlen's $x$-ray work in cranial radiography. To him $I$ am indebted for much raluable assistance. (b) The symptoms presented by the patient as elicited by careful neurological examination. In these neurologioal examinations I have fortunately enjoyed the advantage of the expert advice and guidance of Lieut.-Colonel Gordon Holmes, C.M.G. (c) The actual local findings in the wound and track in the brain at the time of operation.

Each case must be treated on its merits. It will be well 10 discuss the lines of treatment which I have followed in dealing with the following types of injuries.

1. Fissured Fractures without Depression.

In fissured fractures without depression it is only necessary to trephine in those cases in which the patient has ex hibited definite neurological symptoms, such as Jacksonian twitchings or signs of increasing intracranial pressurefor examuple, severe headache, vomiting, increasing optic neuritis, and slow pulse. In such cases a decompression operation is performed and extradural clot removed haemorrhage, if continuing, being appropriately dealt with.

lf the dura is undamaged, in my opinion it should not be opened unless there are indications of large intradural clot, and even then the risk of opening the dura and courting disaster by infecting the subarachnoid space with contaminating sepsis from the wound probably more than counterbalances the risk to the patient's life of leaving the clot to absorb spontaneously if decompression has been efficiently performed by removal of bone and subsequen lumbar puncture. I have been driven to this conclusion as the result of a very sad experience. In my misdirected enthusiasm, engendered by an article written by a heroic cranial surgeon, I opened the dura in a few cases where there was an obvious clot under the dura, with disastrous fatal results.

That the scarring resulting from the absorption and organization of clot and disintegrated brain is more prone to produce epilepsy than the scarring of an open brain track is not proved.

\section{Depressed Fractures without Injury to the Dura.}

Very much the same line of treatment may be adopted where very slight depressions of the inner table have been shown by $x$ rays. Masterly inactivity should be advocatod particularly in those cases in which the outer table is not depressed, and where it is morally certain that no injury to the dura exists. When extensive depression of all tables has occurred and the patient suffers from severe headache, increasing optic neuritis and vomiting, accompanied perhaps by focal symptoms of twitchings or loss of sensation, hemianopia, and so forth, it is advisable to remove the depressed bone, some of which may be elevated and replaced. Should there be a rent in the dura, with free escape of cerebro-spinal fluid, this may be arrested by the application of a muscle eraft to the tear. This will seal it off completely.

\section{Depressed Fractures with Injury to the Dura by} Indriven Fragments of Bone.

If the $x$ rays have demonstrated the presence of $\mathrm{de}$. pressed bone with indriven fragments in the brain, and consequently perforation of the dura, it is usually $m$ practice to trephine just clear of the depressed area, remove the depressed bone by nibbling with a large laminectory forceps or De Vilbi's forceps all round the hole in the bone, so as to expose the healthy dura for at least a quarter of an inch around the dural opening. The brain track is then cleared of indriven bony fragmentis, disintegrated brain matter, and clot. The hole in the bone and the dura may be covered over by a pericranial roof. The scalp wound is then tightly sewn up, a small lateral rubber glove drain being introduced under the scalp down to but not into the dural opening. A direct drainage tube of metal, celluloid, or rubber need only be inserted into the brain track in those cases in which marked sepsis of thio track is evident or suspected, or has been demonstrated by bacteriological examination. In the removal of indriven bone from the brain track the greatest possible care and gentleness must be exercised in order to avoid further injury to the brain, and to obviate the risk of opening up protective adhesions of the subarachnoid space, and lighting up a spreading purulent meningitis. Moreover, there is: a grave danger of opening into the lateral ventricle, which tends to bulge out towards the softened and yieldinge necrotic brain.

The dura should be treated with the greatest respoct. I feel certain that the less interference with, and trimming of, the dura, the less will be the danger of hernia cerebri and meningitis.

A finger may be introduced gently through the hole in the dura into the brain track to feel for fragments of bone; which may be picked out with a pair of dissecting forceps, the intracranial pressure being sufficient to drive many of the smaller pieces, and most of the disintegrated and softened brain substance and clot. (At the discussion which followed this paper Major Harvey Cushing suggested the use of the soft rubber catheter as a sound for detecting fragments of bone. I have employed the catheter, and find that it acts as a satisfactory and efficient sound.)

\section{Penetrating Wounds with Retained Missile in the} Brain.

It may be taken as an axiom that the missile will almost invariably be found to occupy the deepest recess of the brain track, having passed in more deeply than the indriven fragments of bone.

To the question whether all missiles should be remored the answer is unquestionably "No." Some are too large some are too small, some too inaccessible. As a result of Sargent's and Gordon Holmes's investigations into the after-results of cranial injuries, it has been shown that many patients with missiles retained deeply in the brain recover, and are not more liable to serious complications than men whose brains have been lacerated and have not retained foreign bodies. An abscess if it develops usually occurs round a retained infected bony fragment in the track rather than round the missile. If the metal can be easily removed without any further destruction to the brain tissue than that already produced by its entrance it should certainly be extracted. If it is lying deeply in the brain-for example, in the pons-or has passed through. the lateral ventricle in its course, its removal should not be attempted. Surgical intervention in such cases is usually attended with very ill results.

\section{Perforating Wounds through the Brain.}

In the through-and-through perforating wound of the brain, if the bullet has passed through the frontal region from side to side, the entry and exit wounds should be: excised and the routine toilet of the bone and dura carried out, indriven bony fragments being removed. The wounds may then be sutured up and drained by lateral glope or tube drains.

A through-and-through wound from side to side througly both hemispheres in the parietal region has not reached. me at the base hospital. If such a case did arrive so far I should be very conservative, and do littlo more than excise the infected scalp wounds. In two cases in whichi the missile had passed through one hemisphere I hare adopted more heroic methods, and have attempted to 
perform a more radical trephiningroperation. Both patients dfed'with spreading septio encephalitis, which barst into the-Ihterad ventricle; and parulent meningitis.

Haemorrhage from Meningeal Vessels and Sinuses.

Any of the above types of head injury may be associated with haemorrhage from the meningeal vessels or from the larger venous sinuses. So far as possible, the haemorrhage is arrested by means: of a muscle graft taken: from an eninfeetedlarea. In the case of larger sinuses the piece of clean muscle excised from an uninfectediarea is plugged into the lumen of' the sinuss 'The sinus may be compressed by :introdacing a gauza plug between, the dura and the inner surfacei of the skull! Since:employing the muscle. graft method I have not found it necessary to insert gauze into a vessel to arrest haemorrhage, and for some considerable: time I have not passed a ligature through the dura to tie a bleeding vessel, thanks to the efficiency of the peusole grafti when applied. to the surface of the dura aner: the tarn vegsel.

Complications of Trephining.

Onk one or two of the subsequent complications of trephining will be dealt with. Herniation and meningitis natcirally suggest themselves as the most common sequelà in the patients while they remain at the base: hospital. Septicinfection. is the common cause. The treatment in each case is partly similar. The fundamental cause of serious herniation being undoubtedly' septic infection of the brain substance, every possible precaution must be taken to avoid the introduction of infection, and when the brain is once infected to provide for efficient drainage. The careful toilet of the scalp wound and the complete removal of all infected and damaged tissue is therefore essential before trephining. The: liability to the development of a fungus cerebri if the dura is opened and encephalitis ensues, is to my mind one of the strongest arguments against incising an intact dura, or enlarging the bole: of an already opened dura. This lesson has been impressed upon me by my failures.

The extent of the hernia will depend upon the amount of infection, and be proportional to the size of the hole in the dura.

In order to diminish the tendeney to herniation, and to bring the effect of gravity to our assistance in the treatment of hernia cerebri when it has develbped, the patient should as far as possible be made to sit up. in bed with a back rest. The patient should be kept quiet by the administration of bromides, chloral, or morphine: Lumbar punctune should be repeatedly, resorted to. This may be performed under navocain. local anaesthesia in most cases. It is highly undesirable to adiminister a general anaesthetic daily to a man wlio is already very seriously ill when a hammless local anaestlietie can be employed and is found efficient.

The amount of cerebrospinal fluid drawn off averages about half an ounce. It should:be:withdrawn slowly, lest too rapid a. reduction of the intraventricular pressure howld cause an involution of the hernia with breaking down of subaraclinoid' adhesions. This may' lead to a fulminating purulent meningitis.

It.is dangerous to attempt to remove any of the hernia, owing to the very reart risk of opening into a diverticulum of the lateral ventricle, which frequently protrudes into the herniated brain. The hernia should be protected with a ring pad, and kept as clean as possible. If tlie liernia is of moderately firm consistence; light bandage pressure may be applied to thie surface.

Many of the meastures adopted to prevent herniation apply equally in the obviation of meningitis-namely, removal of infected scalp and dirt, abstention from incising the dura unnecessarily, and careful treatment of the mongins of the rent in the dura where it exists, to avoid breaking down recently formed adhesions in the subarachnoid space.

Ftotropin in large doses may be given as a routine with a wiew to rendering the cerebro-spinalffluid sterile. Even when definite meningitis has become established it may be cớnbated'by repeated lumbar puncture. 1 have had several cases in which Captain H: Henry has demonstrated the presence of streptococci, stapliylococci, and $B$. perfringens in the cerebro-spind flivid, wliicli have made a good recovery, although definite olinical signs of meningitis had developed:

I have not had 'sufficient experience of the treatment of intracerebral abscess as the result of gunshot wounds to pronounce any definite opinion thereon.

The subject of epilepsy will: alse be better dealt with by those who have seen the cases after they arxive in England.

Conclusions.

There are a few fundamental principles which, I think, should be followed in tha treatment of oranial injuries:

1. Two stereoscopic a-ray.plates are essential far accurate localization.

2. Careful neurological examination will often elicit signs and symptoms which will guide in operative treatment.

3. All cases should be operated upon early, betore marked sepsis has intervened. The special "head centres" at a casualty clearing station provide for early operative treatment.

4. The durs: shomld be treated with respect, and the risk of hernia cerebri and meningitis when the dura is opened always borne in mind. The dura should be incised only wlien urgent symptoms-demand it, and not merely to avoid phantom symptoms which may, never arise. Headache and a mild degree of "optic neuritis, unless increasing in intensity, are not necessarily indications by themselves.

5. An attempt to remove foreign bodies should be made only in the case of those easily accessible. By "accessible" I mean those which can be removed without producing greatior damage to the brain than that already created by the entry of the missile.

\section{TRAUMATIC ANEURYSM OF THE LEFT SUBCLAVIAN ARTERY :}

SuCCESgFul Ligation at The JunCtion OF The Firgt AND SECOND PORTIONS.

BY

\section{J. SINCLAIR WHITE, M.Ch., F.R.C.S.,} LIEUT.-CoLONEL (R.A.M.C.T.);

G.C. 3rd Nortiern General Hospital; Senior SUrgeon to the

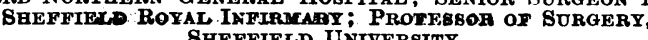
BHEFFIELD UNIVERITY.

THE treatment of aneurysm of the left subclavian artery by ligature of the vessel always presents considerable difficulties, which are the greater the nearer the ligature is applied to the origin of the artery. From the experience of the following case I have been led to draw certain conclusions, which are set out at the end of the report.

Pte. M., aged 35 years, sustained a gunshot wound of the chest on August 16th, 1917, at Ypres: The bullet entere behind to the left of the third dorsal vertebre and escoped just above the olavicte'at a:point corresponding to the: jumotion of the middle and inner thirds of the bone. He spet blood for a day or twa afterwards but the wound progressed favonrably and on August 30 th he was transferred to England: By September 3rd his wound was: soundly healed. Ther. By partial paralysis of the left deltoit muscle, for whiob daily massage and galvanism were presaribed. He continued to passage and galvanism were presaribed. He oontinued to pick up until November 16th, when a pulsating swelling appeared at the roat of the neck. It had all the characters of an aneurysm, and as it steadily increased in size, Colonel A. M. Connell, assisted by Mrjor E. F. Finch, operated on December 8th. The swelling proved to be sacoular aneurysm
arising from the second:part of the subclavian artery. Owing arising from the second part of the subclavian artery. Owing to the dense matting of the tissues around the aneuryam the placing of a proximal ligature was not: attempted. Instead a stout catgut strand was tied around the base of the aneurys where it sprang from the upper convex margin of the artery.

This procedure was for a time followed by marked improvement, and both awelling and. pulsation almost entirely disappeared. Then the aneurysm began to enlarge again, and by the end of. December it had become obvious that, unless something further could be done, it was merely a question of how long he would live. In view of its position and the knowledge that one would have to conduet a deep diseeation throagh tisswes distorted by infiammatory exudate and containing vessels and nerves of the first. Importance, further operativ measures could not be lightly entertained, but, as the alternative seemed wholly black, the facts of his case were placed clearly before him, and he elected to be operated on a poond time. : The eperition took place on January: 2nd, 1918 under chloroform anaesthesia given by Captain $N$. Itilner. I had the valuable assistance of Major G. Wilkinson ond Major E. F. Finch. 